\title{
Perceived need to take medication is associated with medication non-adherence in patients with rheumatoid arthritis
}

This article was published in the following Dove Press journal:

Patient Preference and Adherence

25 November 2014

Number of times this article has been viewed

\author{
Hanneke E Zwikker ${ }^{1,2}$ \\ Sandra van Dulmen ${ }^{3-5}$ \\ Alfons A den Broeder ${ }^{1,2}$ \\ Bart J van den Bemt ${ }^{1,2,6}$ \\ Cornelia $\mathrm{H}$ van den Ende ${ }^{1,2}$ \\ 'Department of Rheumatology, \\ ${ }^{2}$ Department of Pharmacy, Sint \\ Maartenskliniek, Nijmegen, the \\ Netherlands; ${ }^{3}$ Department of Primary \\ and Community Care, Radboud \\ University Medical Centre, Nijmegen, \\ the Netherlands; ${ }^{4}$ NIVEL (Netherlands \\ Institute for Health Services \\ Research), Utrecht, the Netherlands; \\ ${ }^{5}$ Department of Health Science, \\ Buskerud and Vestfold University \\ College, Drammen, Norway; \\ ${ }^{6}$ Department of Pharmacy, Radboud \\ University Medical Centre, Nijmegen, \\ the Netherlands
}

Correspondence: Bart van den Bemt Department of Rheumatology, Sint Maartenskliniek, P.O. Box 90II, 6500 GM Nijmegen, the Netherlands

$\mathrm{Tel}+3 \mathrm{I} 243658213$

$\mathrm{Fax}+3$ I 243659006

Email b.vandenbemt@maartenskliniek.nl
Background: This is the first cross-sectional study that aims to examine associations between beliefs about medication and non-adherence in patients with rheumatoid arthritis (RA) using disease-modifying antirheumatic drugs, taking potential psychological confounders into account.

Methods: Eligible patients (diagnosed with RA for $\geq 1$ year or $\geq 18$ years, using greater than or equal to one disease-modifying antirheumatic drug) were included by their rheumatologist during regular outpatient visits between September 2009 and September 2010. Included patients received questionnaires. The Beliefs about Medicines Questionnaire was used to measure the perceived need to take medication (necessity beliefs), the concerns about taking medication (concern beliefs), general medication beliefs, and attitudes toward taking medication. Medication non-adherence (no/yes) was measured using the Compliance Questionnaire Rheumatology (CQR). Associations between beliefs and non-adherence, and the influence of demographical, clinical, and psychological factors (symptoms of anxiety/depression, illness cognitions, self-efficacy) were assessed using logistic regression.

Results: A total of 580 of the 820 eligible patients willing to participate were included in the analyses (68\% female, mean age 63 years, 30\% non-adherent to their medication). Weaker necessity beliefs (OR [odds ratio]: $0.8,95 \%$ CI [confidence interval]: $0.8-0.9$ ) and an unfavorable balance between necessity and concern beliefs (OR: $0.9,95 \%$ CI: $0.9-1.0$ ) were associated with CQR non-adherence. Also, having an indifferent attitude toward medication (no/yes) was associated with CQR non-adherence (OR: 5.3, 95\% CI: 1.1-25.8), but the prevalence of patients with an indifferent attitude toward medication was low. The associations were barely confounded by demographical, clinical, and psychological factors.

Conclusion: Increasing necessity beliefs about medication in clinical practice might be worthwhile in improving medication adherence in RA patients.

Keywords: medication non-adherence, medication beliefs, psychological confounders, crosssectional studies, rheumatoid arthritis

\section{Introduction}

Disease-modifying antirheumatic drugs (DMARDs) reduce disease activity and radiological progression, and improve long-term functional outcome in patients with rheumatoid arthritis (RA). ${ }^{1}$ However, adherence to DMARDs, ie, the extent to which a patient's medication intake behavior corresponds with agreed recommendations from their health care provider, ${ }^{2}$ is not optimal and ranges from $22 \%$ (underuse) to $107 \%$ (overuse). ${ }^{3-7}$ DMARD non-adherence results in more disease activity/radiological damage, loss of function, and a lower quality of life. ${ }^{8-10}$ Moreover, the annual costs of non-adherence for all conditions in the US have been estimated to be $\$ 100$ billion. ${ }^{11}$ 
In view of the negative implications of medication nonadherence, effective interventions to improve medication adherence are warranted.

Recently, types of non-adherence have been conceptualized as "unintentional" (eg, forgetting medicines) ${ }^{2}$ and "intentional." Intentional non-adherence is driven by a decision not to take medicines as prescribed. According to the NecessityConcerns Framework of Horne and Weinman, ${ }^{12}$ it is assumed that intentional adherence decisions are influenced by a costbenefit assessment. Herein, personal beliefs (assumptions and convictions that are believed to be true by an individual) about the necessity of taking the medication for maintaining or improving health are balanced against concerns about the potential adverse effects (such as nausea and abnormal liver and blood tests, ${ }^{13}$ and also adverse effects like actual medication costs for patients $)^{14}$ of taking the medication.

Many studies underline the importance of addressing these necessity beliefs and concern beliefs about medication to improve adherence. In RA, four studies assessed associations between medication non-adherence and necessity and concern beliefs about medication (measured with the Beliefs about Medicines Questionnaire [BMQ]) ${ }^{15-18}$ In three of the four studies, stronger necessity beliefs were associated with better medication adherence, ${ }^{16-18}$ whereas in one other study, stronger concern beliefs were associated with decreased medication adherence. ${ }^{15}$ Although those studies provide some guidance in targeting the most relevant medication beliefs in clinical practice, they have some limitations.

First, only one of the four studies assessing associations between medication beliefs and non-adherence in RA patients used a valid adherence measure (the dichotomized Compliance Questionnaire Rheumatology [CQR $]$ score, ${ }^{17}$ which was validated against the Medication Event Monitoring System [MEMS]; see Supplementary materials). ${ }^{19}$ Using unvalidated adherence measures might undermine the validity of associations found.

Second, medication beliefs other than necessity and concern beliefs measured with the BMQ are suggested to be associated with non-adherence ${ }^{16,20-22}$ but are not often included in the existing research. These constructs comprise four attitudinal patient profiles toward taking medication (ie, "skeptical", “indifferent", “ambivalent”, and "accepting”), and general beliefs about the potential of medication to harm and about overuse of medication by clinicians. In RA, only one study assessed associations between the general medication beliefs and adherence. This study demonstrated that the belief that physicians do not overuse medication was related to better adherence. ${ }^{16}$ More studies are needed, however, to know the extent to which these constructs are associated with medication non-adherence in RA patients.

Third, no single study (in- and outside the field of RA) examining associations between medication beliefs and non-adherence took psychological factors such as anxiety/depression, self-efficacy, and illness cognitions simultaneously into account in the data-analysis, while they appear to play a central role in explaining medication non-adherence. ${ }^{23,24}$ These factors might also be associated with beliefs about medication, moreover, and might thus be potential confounders of associations between beliefs about medication and non-adherence. It is conceivable that patients with stronger accepting cognitions about their illness also have more positive views about their medication, and thus, have better medication adherence than patients who do not accept their illness, for example.

The aim of this cross-sectional study is to examine associations between the total range of beliefs about medication (as measured with the BMQ) and medication non-adherence in RA patients using DMARDs, using the dichotomized CQR adherence measure, and taking potential psychological, demographical, and clinical confounders into account. The results of our study could provide starting points for the development of interventions to improve adherence.

\section{Patients and methods}

This study is approved by the local medical ethical board (CMO 2009/090) and is reported according to the Strengthening the Reporting of Observational Studies in Epidemiology guidelines. $^{25}$

\section{Design, patients, and procedure}

This cross-sectional study was conducted at the Sint Maartenskliniek (a clinic specializing in rheumatology, rehabilitation, and orthopedic surgery) in Nijmegen, the Netherlands. Consecutive RA patients were screened for eligibility by their rheumatologist during regular outpatient visits between September 2009 and September 2010. Inclusion criteria were having RA for at least 1 year (because medication beliefs are still to be formed in patients newly diagnosed with RA) ${ }^{26}$ according to the 2010 American College of Rheumatology criteria, ${ }^{27}$ being $\geq 18$ years old, and using $\geq 1$ prescribed DMARD. Having severe mental or physical constraints and being illiterate in the Dutch language were exclusion criteria. Eligible patients willing to participate received study information and a set of questionnaires at their home address. Reminders were sent after 2 weeks. All included patients had signed informed consent. 


\section{Measures}

Unless indicated otherwise, items were measured by selfreport questionnaires.

\section{Beliefs about medication}

Beliefs about medication were measured using two parts of the validated BMQ: ${ }^{28}$ the BMQ "specific" and the BMQ "general."

The BMQ "specific" has two subscales of five items each, measuring patients' beliefs about the necessity of prescribed medication (eg, "Without my medicines I would be very ill") and their concerns about potential adverse consequences of taking the medication. Within the subscales, items are scored from 5 (strongly agree) to 1 (strongly disagree) and are summed to obtain a total score ranging from 5 to 25 . Higher scores indicate stronger beliefs. By subtracting the concern score from the necessity score, a necessity-concerns differential score can be calculated (ranging from -20 to +20 , where positive scores mean that patients perceive that benefits of medication outweigh costs, and vice versa). Necessity and concern scores were dichotomized at the scale midpoint to create four attitudinal profiles: "skeptical" (low necessity, high concerns [score $<15$ or $\geq 15$, respectively]), "indifferent" (low necessity, low concerns), "ambivalent" (high necessity, high concerns), and "accepting" (high necessity, low concerns). ${ }^{20,22}$

The BMQ "general" assesses general beliefs about pharmaceuticals as a class of treatment, ${ }^{20}$ and has two subscales of four items each. The "overuse" subscale includes beliefs about the way in which medicines are endorsed by doctors (eg, "Doctors place too much trust on medicines"). The "harm" subscale includes beliefs about the potential of medication to harm (eg, "Medicines do more harm than good"). The scoring method is identical to the BMQ "specific": total subscale scores range from 4 to 20 .

\section{Medication non-adherence}

Medication non-adherence was primarily assessed with the CQR. The CQR has been validated using MEMS in RA patients, ${ }^{19}$ and is able to detect whether a patient takes $\leq 80 \%$ of prescribed medication (binary score: non-adherent versus adherent patients) with a sensitivity of $62 \%$ and a specificity of $95 \%$. Details about calculation of the CQR-score are provided in the Supplementary materials section.

The five-item Medication Adherence Report Scale (MARS $)^{29}$ was used as an alternative measure for non-adherence in a sensitivity analysis. MARS includes statements about stopping, forgetting, or altering medication doses. Items are summed to obtain a total score ranging from 5 to 25 , where higher scores meant better adherence. Because the MARS score was severely skewed in this study, we dichotomized the score at $95 \%$ of its scale (non-adherent when total score $\leq 23) \cdot{ }^{17,30}$

\section{Potential confounders}

Sociodemographic factors measured were age, sex, living with others (yes/no), educational level (high/not high, where "high" means having at least a bachelor or master degree), and employment/studying (yes/no).

Clinical factors measured were disease duration, disease activity (Rheumatoid Arthritis Disease Activity Index), ${ }^{31}$ pain (Visual Analog Scale), ${ }^{32,33}$ and physical abilities (Health Assessment Questionnaire); ${ }^{32}$ see Table S1 for details. Electronic hospital/pharmacy data ${ }^{34}$ were used to assess the types of DMARDs taken at the time of filling in the questionnaires and to assess the presence of anti-CCP (cyclic citrullinated peptide antibody) and rheumatoid factor values in the participants (for descriptive purposes only).

Three psychological factors were measured. The Illness Cognition Questionnaire ${ }^{35}$ encompasses three generic illness cognitions, namely "helplessness" as a way of emphasizing the aversive meaning of a disease, "acceptance" as a way to diminish this aversive meaning, and "perceived benefits" as a way of adding a positive meaning to a disease. Self-efficacy related to physical function, to coping with pain, and to coping with other symptoms associated with arthritis (such as depression and fatigue) was measured with the Arthritis SelfEfficacy Scale. ${ }^{36,37}$ Last, feelings of anxiety/depression were measured by the Hospital Anxiety and Depression Scale. ${ }^{38}$ For details about the questionnaires, see Table $\mathrm{S} 1$.

All questionnaires used are validated tools and demonstrated to have a sufficient internal consistency in this RA sample. Cronbach's alpha varied from 0.68 to 0.97 .

\section{Sample size and data analyses}

As we aimed to adjust for approximately 25 variables in our data analyses, we aimed to include at least 500 RA patients in this cross-sectional study. ${ }^{39}$

Differences between study participants and patients who refused to participate were tested by means of chi-square tests, two sample $t$-tests, or non-parametric tests in case of skewed distributions. Then, correlation coefficients between all pairs of variables were studied to detect multicollinearity: non-psychological factors were removed from further analyses when $r \geq 80$ (oral conversation with Drs P Spreeuwenberg, statistician, NIVEL, September 2013). The psychological factors were all included in further analyses to study their 
influence on associations between beliefs about medication and non-adherence.

Subsequently, associations between all scales of beliefs about medication and non-adherence were analyzed by logistic regression models in three steps, with robust standard errors $^{40}$ and a two-sided $\alpha$ set at 0.05 . Univariate, unadjusted models were fit in Step 1. In Step 2, demographic and clinical measures were forced into the models attained in Step 1, and in the last step, the psychological factors were forced into the models attained in Step 2. In a sensitivity analysis, we repeated all steps with the MARS as a non-adherence measure. Note that the four attitudinal profiles (Measures section) were handled as dichotomous variables in the analyses (eg, patients with a skeptical attitude versus the rest of the patients, whereby "the rest of the patients" were the reference group).

Analyses were performed in STATA10, were based on complete cases, and were verified by a statistician.

\section{Results}

Participants

A total of $580(71 \%)$ of the 820 eligible patients willing to participate were included in the analyses (Figure 1). The
580 patients who returned the questionnaires did not differ on age and sex from the 240 patients who did not return the questionnaires.

Most participants were female and lived together with other people. Less than $20 \%$ of the participants were highly educated. Also, the majority of participants used one DMARD and had a median disease duration of 14 years (Table 1).

\section{Non-adherence and psychological factors}

In all, 171 of 575 of participants filling in the CQR were non-adherent to their medication (29.7\%). This was $33.6 \%$ (of 562 participants) according to the MARS. The correlation between the two adherence measures was low (Spearman's rho $=0.28, P<0.01)$.

Participants had stronger necessity beliefs than concern beliefs about medication, and the majority of participants had an accepting or ambivalent attitude toward their DMARD medication (Table 2).

\section{Associations between beliefs about medication and non-adherence}

Unadjusted and adjusted associations between the BMQ constructs and CQR non-adherence are displayed in Table 3.

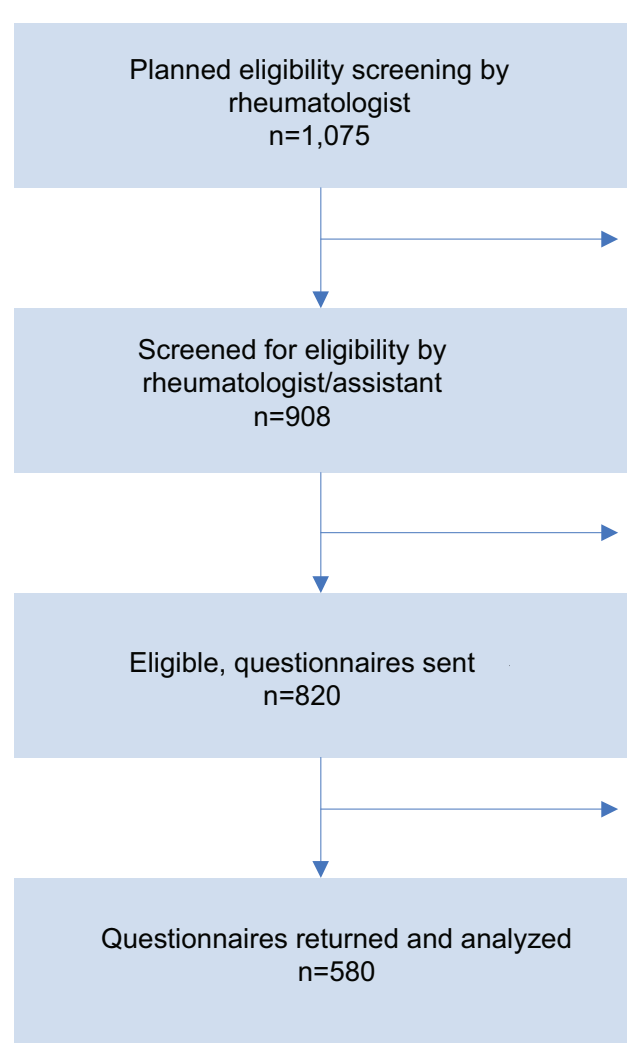

Figure I Participant flow chart.

Abbreviation: DMARDs, disease-modifying antirheumatic drugs.
Not screened $(n=167)$

Objection of patients $\quad n=115$

Not enough time for screening during outpatient visit $\quad n=52$

\section{Not eligible $(n=88)$}

No rheumatoid arthritis

No use of DMARDs

Not able to participate, mentally

Not able to participate, physically

Not able to participate, communicatively

Objection of rheumatologist, multiple of above reasons

Objection of rheumatologist, unknown reasons

\section{Non-response due to $(n=240)$}

Personal conditions (eg, considering oneself too old, too weak, too busy, family affairs)

Questionnaire content (eg, too many or too personal questions)

Not using medication at that time

Questionnaire not returned, reasons unknown $\mathrm{n}=22$

$\mathrm{n}=13$

$\mathrm{n}=16$

$\mathrm{n}=12$

$\mathrm{n}=11$

$n=8$

$n=6$

$n=14$

$n=11$

$\mathrm{n}=4$

$\mathrm{n}=211$ 
Table I Sample characteristics

\begin{tabular}{|c|c|c|}
\hline Variables & $\begin{array}{l}\text { Number of } \\
\text { patients } \\
\text { providing data }\end{array}$ & Descriptives \\
\hline \multicolumn{3}{|l|}{ Sociodemographic factors } \\
\hline Age (years) & 580 & $62.8(12.6)$ \\
\hline Female & 580 & $396(68.3 \%)$ \\
\hline Living with others & 571 & $458(80.2 \%)$ \\
\hline High education ${ }^{\#}$ & 571 & $106(18.6 \%)$ \\
\hline Currently employed or studying & 552 & $216(39.1 \%)$ \\
\hline \multicolumn{3}{|l|}{ Clinical factors } \\
\hline Disease duration (years) & 556 & $14(8-22)$ \\
\hline \multicolumn{3}{|l|}{ Number of DMARDs used } \\
\hline One DMARD & 476 & 307 (64.5\%) \\
\hline Two DMARDs & 476 & $149(31.3 \%)$ \\
\hline Three DMARDs & 476 & $20(4.2 \%)$ \\
\hline \multicolumn{3}{|l|}{ Route of DMARD administration } \\
\hline $\mathrm{Oral}^{\ddagger}$ & 476 & $272(57.1 \%)$ \\
\hline Parenteral ${ }^{\S}$ & 476 & $296(62.2 \%)$ \\
\hline Rheumatoid factor (positive)" & 332 & $260(78.3 \%)$ \\
\hline Anti-CCP (positive)" & 284 & $199(70.1 \%)$ \\
\hline $\begin{array}{l}\text { RADAI disease activity } \\
(0-10)^{\pi}\end{array}$ & 493 & $2.7(1.9)$ \\
\hline VAS pain score & 550 & $30.8(22.4)$ \\
\hline$(0-100 \mathrm{~mm})^{\pi}$ & & \\
\hline HAQ-DI $(0-3)^{\pi}$ & 563 & I.I (0.8) \\
\hline
\end{tabular}

Notes: Data are means (standard deviation), medians (interquartile range), or numbers (\%). \#High education means having at least a bachelor or master degree. ${ }^{\ddagger}$ Azathioprine, hydroxychloroquine, leflunomide, methotrexate, predinosone/ predinsolone, or sulfasalazine. ${ }^{\S}$ Adalimumab, aurothiomalate, methylprednisolone, etanercept, methotrexate, abatacept, infliximab, tocilizumab, or rituximab. "For descriptive purposes only, so not included in further analysis. "Higher scores indicate more disease activity/pain/disability.

Abbreviations: DMARDs, disease-modifying antirheumatic drugs; Anti-CCP value, anti-cyclic citrullinated peptide antibody; RADAI, Rheumatoid Arthritis Disease Activity Index; VAS, Visual Analog Scale; HAQ-DI, Health Assessment Questionnaire Disability Index.

The significant associations between continuously measured BMQ constructs and non-adherence of Step 3 (Table 3) are also visually presented in Figure 2 .

The Health Assessment Questionnaire-scale was removed from the analyses due to multicollinearity with the Arthritis Self-Efficacy Scale physical functioning scale.

After adjustment of all potential confounders, (weaker) necessity beliefs, a more unfavorable balance between necessity and concern beliefs, and having an indifferent attitude toward medication were associated with CQR nonadherence. The post hoc analysis revealed that patients with an indifferent attitude toward medication were less adherent to medication compared to patients with an ambivalent or accepting attitude (chi-square tests, $P=0.001$ ). Overall, the general medication beliefs (the harm and overuse scales) were not associated with non-adherence.

Demographical and clinical factors barely influenced associations between beliefs about medication and CQR non-adherence (Step 2, Table 3), as did the psychological
Table 2 Psychological factors

\begin{tabular}{|c|c|c|}
\hline Variables & $\begin{array}{l}\text { Number of } \\
\text { patients } \\
\text { providing data }\end{array}$ & Descriptives \\
\hline \multicolumn{3}{|l|}{ Beliefs about medication } \\
\hline Necessity beliefs $(5-25)^{\#}$ & 536 & $19.9(3.5)$ \\
\hline Concerns beliefs $(5-25)^{\#}$ & 535 & $14.3(3.6)$ \\
\hline $\begin{array}{l}\text { Necessity-concerns } \\
\text { differential }(-20 \text { till }+20)^{\ddagger}\end{array}$ & 527 & $5.6(4.7)$ \\
\hline Overuse beliefs $(4-20)^{\#}$ & 546 & $10.3(2.5)$ \\
\hline Harm beliefs (4-20)\# & 542 & $10.2(2.5)$ \\
\hline Attitudinal profiles: & 527 & 14 (2.7\%) \\
\hline \multicolumn{3}{|l|}{ Skeptical } \\
\hline Indifferent & 527 & $25(4.7 \%)$ \\
\hline Ambivalent & 527 & $244(46.3 \%)$ \\
\hline Accepting & 527 & $244(46.3 \%)$ \\
\hline \multicolumn{3}{|l|}{ ICQ illness cognitions $(6-24)^{\#}$} \\
\hline Helplessness & 542 & II.7 (4.2) \\
\hline Acceptance & 544 & $17.8(3.8)$ \\
\hline Perceived benefits & 538 & I $4.2(4.5)$ \\
\hline \multicolumn{3}{|l|}{ UVR self-efficacy $(I-5)^{\#}$} \\
\hline Pain & 570 & $3.6(0.8)$ \\
\hline Physical functioning & 566 & $3.8(1.1)$ \\
\hline Symptoms & 559 & $3.9(0.8)$ \\
\hline $\begin{array}{l}\text { HADS anxiety/depression } \\
(0-42)^{\#}\end{array}$ & 567 & $9.3(6.5)$ \\
\hline
\end{tabular}

Notes: Data are means (standard deviation) or numbers (\%). "Higher scores indicate stronger beliefs, more helplessness/acceptance/perceived benefits, stronger self-efficacy concerning pain/physical functioning/symptoms, and more anxiety and depression. ${ }^{\text {DDifferential }}=$ necessity score minus concerns score. Positive score means that necessity beliefs about medication are stronger than concern beliefs about medication.

Abbreviations: ICQ, Illness Cognition Questionnaire; UVR, Arthritis Self-Efficacy Scale; HADS, Hospital Anxiety and Depression Scale.

factors (Step 3, Table 3). The significant association between having an indifferent attitude toward medication and nonadherence, however, was confounded by illness cognitions (perceived benefits of the disease). For details about the contribution of single, psychological factors to associations between beliefs about medication and non-adherence, see Table S2.

\section{Sensitivity analysis}

We repeated all analyses with the MARS (data not shown). Now, only (weaker) necessity beliefs about medication were associated with MARS non-adherence after adjustment for all confounders (odds ratio [OR]: 0.9, 95\% CI: 0.8-1.0). Findings were robust regarding the role of demographical, clinical, and psychological confounders.

\section{Discussion}

This is the first cross-sectional study that assessed associations between the total range of beliefs about medication as measured with the BMQ and medication non-adherence in a large sample of patients with RA, using a valid adherence 
Table 3 Associations between beliefs about medication and CQR non-adherence

\begin{tabular}{|c|c|c|c|}
\hline \multirow[t]{2}{*}{ BMQ constructs } & \multicolumn{3}{|c|}{ CQR non-adherence, OR (95\% Cl) } \\
\hline & $\begin{array}{l}\text { Unadjusted: Step I } \\
(n=524-543)\end{array}$ & $\begin{array}{l}\text { Adjusted: Step 2* } \\
(\mathrm{n}=332-344)\end{array}$ & $\begin{array}{l}\text { Adjusted: Step 3\# } \\
(n=297-307)\end{array}$ \\
\hline Necessity beliefs & $0.9(0.8-0.9)^{\ddagger}$ & $0.8(0.8-0.9)^{\ddagger}$ & $0.8(0.8-0.9)^{\ddagger}$ \\
\hline Concerns beliefs & $1.0(0.9-1.0)$ & $1.0(0.9-1.1)$ & $1.0(0.9-1.1)$ \\
\hline Necessity-concerns differential & $0.9(0.9-1.0)^{\ddagger}$ & $0.9(0.9-1.0)^{\ddagger}$ & $0.9(0.9-1.0)^{\ddagger}$ \\
\hline Overuse beliefs & I.I (I.0-I.I) & I.I $(1.0-1.2)^{\S}$ & I.I (1.0-1.2) \\
\hline Harm beliefs & I.0 (0.9-I.I) & I.I (I.0-I.2) & I.I (0.9-1.2) \\
\hline \multicolumn{4}{|l|}{ Attitudinal profiles" } \\
\hline Skeptical & $2.5(0.9-7.2)$ & $1.8(0.5-5.9)$ & $1.8(0.5-6.0)$ \\
\hline Indifferent & $3.9(1.7-8.9)^{\ddagger}$ & $5.0(1.3-19.3)^{\S}$ & $5.3(\mathrm{I} . \mathrm{I}-25.8)^{\S}$ \\
\hline Ambivalent & $0.8(0.5-1.2)$ & $0.8(0.5-1.4)$ & $0.7(0.4-1.4)$ \\
\hline Accepting & $0.8(0.6-1.2)$ & $0.9(0.5-1.5)$ & $0.9(0.5-1.7)$ \\
\hline
\end{tabular}

Notes: *In Step 2, models were adjusted for age, sex, living with others (yes/no), high education (yes/no), currently employed or studying (yes/no), disease duration, n DMARDs used, route of DMARD administration, disease activity (RADAI), and pain (VAS). "In Step 3, models were adjusted for the same factors as in Step 2, and additionally for illness cognitions (ICQ), self-efficacy (UVR), and anxiety/depression (HADS). The HAQ was left out as potential confounder due to multicollinearity with the UVR physical functioning scale. ${ }^{\prime} \leq 0.01, \$ P \leq 0.05$. "Reference group $=$ "rest of the patients." So, for example, the odds for being non-adherent to medication is bigger for patients with a skeptical attitude toward medication compared with patients with a non-skeptical attitude toward medication.

Abbreviations: CQR, Compliance Questionnaire Rheumatology; BMQ, Beliefs about Medicines Questionnaire; OR, odds ratio; Cl, confidence interval; DMARD, diseasemodifying antirheumatic drug; RADAI, Rheumatoid Arthritis Disease Activity Index; VAS, Visual Analog Scale; ICQ, Illness Cognition Questionnaire; UVR, Arthritis SelfEfficacy Scale; HADS, Hospital Anxiety and Depression Scale; HAQ, Health Assessment Questionnaire; n DMARDs, number of disease-modifying antirheumatic drugs.

measure and taking (among others) psychological factors into account. Weaker necessity beliefs, a more unfavorable balance between necessity and concern beliefs, and having an indifferent attitude toward medication were associated with CQR non-adherence. Psychological, demographical, and clinical factors hardly influenced associations found, and thus, some constructs of the BMQ appear to be independent predictors of medication non-adherence in RA patients.

Having weaker necessity beliefs about medication was the only BMQ construct that was independently associated with both CQR and MARS non-adherence. The strength of the associations was considerable, as a two unit increase on the BMQ necessity scale, for instance, would already yield an $\mathrm{OR}$ of 0.6 (ie, $\left.\mathrm{OR}=0.8^{2}\right)^{41}$ for patients in being non-adherent to medication. This implies that necessity beliefs about

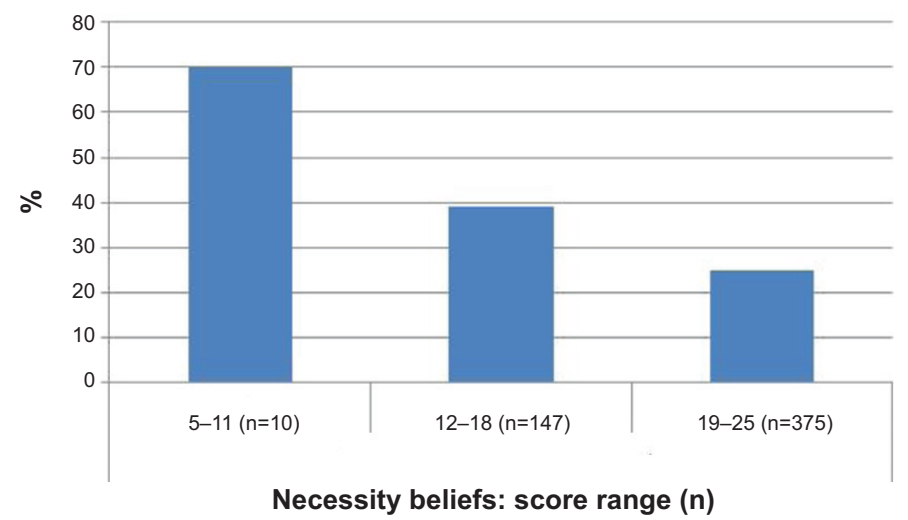

Figure 2 Percentage of non-adherent patients per BMQ score range. Abbreviation: BMQ, Beliefs about Medicines Questionnaire. medication are a sensible target for adherence-improving interventions.

According to our results, necessity beliefs about medication, and not concern beliefs about medication, were associated with medication non-adherence. This corresponds with three ${ }^{16-18}$ of the four ${ }^{15-18}$ previous studies assessing associations between beliefs about medication and nonadherence in RA patients. An explanation for necessity beliefs about medication being more important in explaining non-adherence than concern beliefs about medication might be that feeling the need to take medication is a prerequisite for actually taking medicines. So, regardless of the level of concerns about medication, patients probably will not take their medication if they do not perceive taking medication as being necessary.

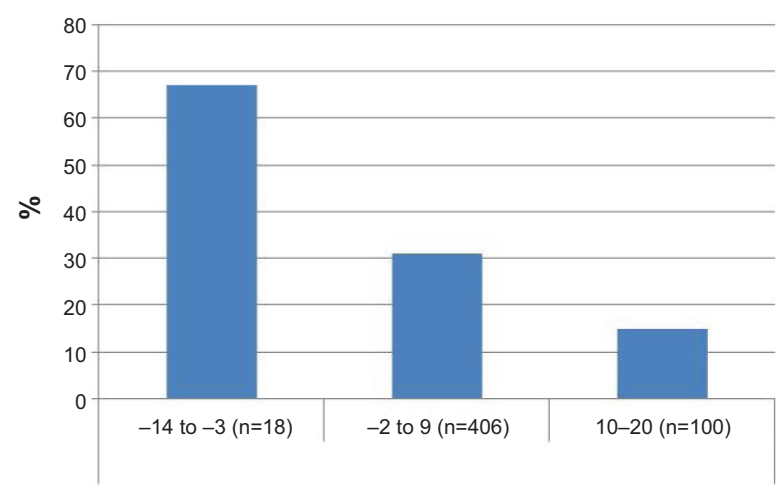

Necessity-concerns differential: score range (n) 
In contrast to most other studies, we were able to examine the role of the general medication beliefs in predicting nonadherence next to the role of necessity and concern beliefs about medication. Overall, our results indicate that there were no associations between these general harm and general overuse beliefs about medication and non-adherence. An explanation might be that general beliefs are most relevant when new and unfamiliar treatment is prescribed. Their influence might diminish when patients become more familiar with their treatment and as a consequence, start to develop necessity and concerns beliefs about their medication. ${ }^{16}$

We were the first to assess associations between the attitudinal profiles and non-adherence in patients with RA. Corresponding to other studies, ${ }^{20-22}$ more non-adherence was present in patients with an indifferent attitude toward medication compared to patients with an ambivalent or accepting attitude toward medication. Maybe, patients with an indifferent attitude toward their medication might feel less dependent on their medication for controlling their disease. This thought is supported by our data; it appears that patients with an indifferent attitude toward medication feel less helpless than patients with a non-indifferent attitude toward medication (regression coefficient $b:-2.1$, 95\% CI: $-3.8,-0.4)$. Also, they have a higher self-efficacy related to physical functioning ( $b: 0.5,95 \% \mathrm{CI}: 0.1,1.0)$. An alternate explanation might be that patients with an indifferent attitude toward their medication might also have an indifferent attitude toward their health in general.

This study has its strengths and limitations regarding internal validity. The first strength is that we assessed associations in a large sample of RA patients. Second, we were the first to correct for feelings of anxiety/depression, illness cognitions, and self-efficacy when modeling associations between beliefs about medication and non-adherence, and third, we used the validated, dichotomized CQR-score as the main adherence measure. However, the CQR is a self-report measure of adherence. Self-report measures of adherence reflect the patients' motivation and ability to take medication, while adherence measured by electronic pill count or pharmacy refill data, for example, reflect a different concept: availability of medication. ${ }^{18,42}$ Hence, caution is necessary when comparing our results based on self-report with results obtained by other adherence measurement methods. ${ }^{18,43}$ Also, true ingestion of medication could not be proved by self-report. Most other adherence measurement methods also suffer from this limitation, however. ${ }^{2}$ We believe that using the CQR for adherence measurement was the best choice for this study, because it has been validated against the MEMS in RA patients, questionnaires are easy to use, and no gold standard to measure adherence is available. ${ }^{2}$

Due to the cross-sectional design of this study, we were not able to assess the causality of associations between beliefs about medication and non-adherence. So, it is unclear if beliefs about medication led to non-adherence or whether non-adherent behavior influenced beliefs. ${ }^{44}$ However, there still is insufficient knowledge about the presence (or absence) of longitudinal associations between beliefs about medication and non-adherence. ${ }^{45}$ Like adherence itself, beliefs about medication might change over time. A high level of necessity beliefs about medication might correlate well with adherent behavior at that same time, but might not be predictive of adherent behavior in the future. So, cross-sectional designs might be as informative as longitudinal designs.

This study also has its strengths and limitations regarding external validity. On average, our sample of RA patients had a long disease duration (median: $>14$ years), making our results not generalizable to patients with recently diagnosed RA. However, our population did not differ from other RA populations ${ }^{15-17}$ on other demographic and clinical characteristics, making our results generalizable to RA populations with a long disease duration.

\section{Practice implications}

Attempts to increase necessity beliefs about medication in RA patients might be worthwhile in improving medication adherence. However, strong evidence about effective interventions to increase necessity beliefs about medication is currently absent. Development of such interventions and research into the effectiveness of these interventions is needed.

Although the strength of the association between having an indifferent attitude towards medication and medication non-adherence was considerable, targeting patients with such an indifferent attitude is not sensible in clinical practice because of the low prevalence $(4 \% ; 580$ patients need to be screened to detect 25 indifferent patients).

\section{Conclusion}

Weaker necessity beliefs about medication, a more unfavorable balance between necessity and concern beliefs about medication, and having an indifferent attitude toward medication are associated with medication non-adherence. Psychological factors hardly confound those associations. Of the BMQ constructs associated with non-adherence, increasing necessity beliefs about medication in clinical practice might be most worthwhile to improve medication adherence in RA patients. 


\section{Acknowledgment}

We would like to thank Peter Spreeuwenberg for his advice regarding the statistical analyses.

\section{Disclosure}

The authors report no conflicts of interest in this work.

\section{References}

1. Jones G, Halbert J, Crotty M, Shanahan EM, Batterham M, Ahern M. The effect of treatment on radiological progression in rheumatoid arthritis: a systematic review of randomized placebo-controlled trials. Rheumatology (Oxford). 2003;42(1):6-13.

2. van den Bemt BJ, Zwikker HE, van den Ende CH. Medication adherence in patients with rheumatoid arthritis: a critical appraisal of the existing literature. Expert Rev Clin Immunol. 2012;8(4):337-351.

3. Blum MA, Koo D, Doshi JA. Measurement and rates of persistence with and adherence to biologics for rheumatoid arthritis: a systematic review. Clin Ther. 2011;33(7):901-913.

4. Brus H, van de Laar M, Taal E, Rasker J, Wiegman O. Determinants of compliance with medication in patients with rheumatoid arthritis: the importance of self-efficacy expectations. Patient Educ Couns. 1999; 36(1):57-64.

5. Doyle DV, Perrett D, Foster OJ, Ensor M, Scott DL. The long-term use of D-penicillamine for treating rheumatoid arthritis: is continuous therapy necessary? Br J Rheumatol. 1993;32(7):614-617.

6. Koncz T, Pentek M, Brodszky V, Ersek K, Orlewska E, Gulacsi L. Adherence to biologic DMARD therapies in rheumatoid arthritis. Expert Opin Biol Ther. 2010;10(9):1367-1378.

7. Pullar T, Peaker S, Martin MF, Bird HA, Feely MP. The use of a pharmacological indicator to investigate compliance in patients with a poor response to antirheumatic therapy. Br J Rheumatol. 1988;27(5):381-384.

8. Contreras-Yanez I, Ponce De LS, Cabiedes J, Rull-Gabayet M, Pascual-Ramos V. Inadequate therapy behavior is associated to disease flares in patients with rheumatoid arthritis who have achieved remission with disease-modifying antirheumatic drugs. Am J Med Sci. 2010; 340(4):282-290.

9. van den Bemt BJF. Optimizing Pharmacotherapy in Patients with Rheumatoid Arthritis: An Individualized Approach. The Netherlands: Radboud University Nijmegen; 2009.

10. VillerF, Guillemin F, Briancon S, Moum T, Suurmeijer T, van den Heuvel W. Compliance to drug treatment of patients with rheumatoid arthritis: a 3 year longitudinal study. J Rheumatol. 1999;26(10):2114-2122.

11. Osterberg L, Blaschke T. Adherence to medication. NEngl J Med. 2005; 353(5):487-497.

12. Horne R, Weinman J. Patients' beliefs about prescribed medicines and their role in adherence to treatment in chronic physical illness. J Psychosom Res. 1999;47(6):555-567.

13. Bijlsma JWJ. Principles of rehabilitation in rheumatic diseases. In: Burmester GR, Da Silva JAP, Faarvang KL, Hachulla E, Mariette X, editors. Eular Compendium on Rheumatic Diseases. 1st ed. London and Kilchberg (Switserland): BMJ Publishing Group/European League against Rheumatism; 2009.

14. Kardas P, Lewek P, Matyjaszczyk M. Determinants of patient adherence: a review of systematic reviews. Front Pharmacol. 2013;4:91.

15. Neame R, Hammond A. Beliefs about medications: a questionnaire survey of people with rheumatoid arthritis. Rheumatology (Oxford). 2005;44(6):762-767.

16. Treharne GJ, Lyons AC, Kitas GD. Medication adherence in rheumatoid arthritis: effects of psychosocial factors. Psychol Health Med. 2004;9(3):337-349.

17. van den Bemt BJF, van den Hoogen FH, Benraad B, Hekster YA, van Riel PL, van Lankveld W. Adherence rates and associations with nonadherence in patients with rheumatoid arthritis using disease modifying antirheumatic drugs. J Rheumatol. 2009;36(10):2164-2170.
18. de Thurah A, Norgaard M, Harder I, Stengaard-Pedersen K. Compliance with methotrexate treatment in patients with rheumatoid arthritis: influence of patients' beliefs about the medicine. A prospective cohort study. Rheumatol Int. 2010;30(11):1441-1448.

19. de Klerk E, van der Heijde D, Landewe R, van der Tempel H, van der Linden $\mathrm{S}$. The compliance-questionnaire-rheumatology compared with electronic medication event monitoring: a validation study. J Rheumatol. 2003;30(11):2469-2475.

20. Menckeberg TT, Bouvy ML, Bracke M, et al. Beliefs about medicines predict refill adherence to inhaled corticosteroids. J Psychosom Res. 2008;64(1):47-54.

21. Moshkovska T, Stone MA, Clatworthy J, et al. An investigation of medication adherence to 5 -aminosalicylic acid therapy in patients with ulcerative colitis, using self-report and urinary drug excretion measurements. Aliment Pharmacol Ther. 2009;30(11-12):1118-1127.

22. Tibaldi G, Clatworthy J, Torchio E, Argentero P, Munizza C, Horne R. The utility of the Necessity-Concerns Framework in explaining treatment non-adherence in four chronic illness groups in Italy. Chronic Illn. 2009;5(2):129-133.

23. DiMatteo MR, Lepper HS, Croghan TW. Depression is a risk factor for noncompliance with medical treatment: meta-analysis of the effects of anxiety and depression on patient adherence. Arch Intern Med. 2000; 160(14):2101-2107.

24. Elliott RA. Poor adherence to medication in adults with rheumatoid arthritis: reasons and solutions. Dis Manage Health Outcomes. 2008; 16(1):13-29.

25. Vandenbroucke JP, Von Elm E, Altman DG, et al; Iniciativa STROBE. [Strengthening the reporting of observational studies in epidemiology (STROBE): explanation and elaboration]. Gac Sanit. 2009; 23(2): 158

26. Willey C, Redding C, Stafford J, et al. Stages of change for adherence with medication regimens for chronic disease: development and validation of a measure. Clin Ther. 2000;22(7):858-871.

27. Aletaha D, Neogi T, Silman AJ, et al. 2010 Rheumatoid arthritis classification criteria: an American College of Rheumatology/European League Against Rheumatism collaborative initiative. Arthritis Rheum. 2010;62(9):2569-2581.

28. Horne R, Weinman J, Hankins M. The Beliefs about Medicines Questionnaire: the development and evaluation of a new method for assessing the cognitive representation of medication. Psychol Health. 1999;14(1):1-24.

29. Horne R. The Medication Adherence Report Scale (MARS): A New Measurement Tool for Eliciting Patients' Report non-Adherence. [Working paper]. Mayfield House, United Kingdom: University of Brighton; 2013.

30. Butler JA, Peveler RC, Roderick P, Horne R, Mason JC. Measuring compliance with drug regimens after renal transplantation: comparison of self-report and clinician rating with electronic monitoring. Transplantation. 2004;77(5):786-789.

31. Fransen J, Langenegger T, Michel BA, Stucki G. Feasibility and validity of the RADAI, a self-administered rheumatoid arthritis disease activity index. Rheumatology (Oxford). 2000;39(3):321-327.

32. Bruce B, Fries JF. The Stanford Health Assessment Questionnaire: dimensions and practical applications. Health Qual Life Outcomes. 2003;1:20.

33. Price DD, Bush FM, Long S, Harkins SW. A comparison of pain measurement characteristics of mechanical visual analogue and simple numerical rating scales. Pain. 1994;56:217-226.

34. Grijalva CG, Chung CP, Arbogast PG, Stein CM, MitchelEF Jr, Griffin MR. Assessment of adherence to and persistence on disease-modifying antirheumatic drugs (DMARDs) in patients with rheumatoid arthritis. Med Care. 2007;45(10 Supl 2):S66-S76.

35. Evers AW, Kraaimaat FW, van Lankveld W, Jongen PJ, Jacobs JW, Bijlsma JW. Beyond unfavorable thinking: the illness cognition questionnaire for chronic diseases. J Consult Clin Psychol. 2001;69(6):1026-1036.

36. Lorig K, Chastain RL, Ung E, Shoor S, Holman HR. Development and evaluation of a scale to measure perceived self-efficacy in people with arthritis. Arthritis Rheum. 1989;32(1):37-44. 
37. Riemsma RP, Taal E, Rasker JJ. Group education for patients with rheumatoid arthritis and their partners. Arthritis Rheum. 2003; 49(4):556-566.

38. Zigmond AS, Snaith RP. The hospital anxiety and depression scale. Acta Psychiatr Scand. 1983;67(6):361-370.

39. Francis G. Introduction to SPSS for Windows: v. 15.0 and 14.0 with Notes for Studentware (5e). 5th ed. Melbourne: Pearson Australia; 2007.

40. StataCorp LP. Stata User's Guide release 11. Texas, USA: Stata Press; 2009.

41. Twisk JWR. Inleiding in de toegepaste biostatistiek [Introduction in Applied Biostatistics]. 2th ed. Maarssen: Elsevier Gezondheidszorg; 2010. Dutch.

42. Liu H, Golin CE, Miller LG, et al. A comparison study of multiple measures of adherence to HIV protease inhibitors. Ann Intern Med. 2001 134(10):968-977.
43. Guenette L, Moisan J, Preville M, Boyer R. Measures of adherence based on self-report exhibited poor agreement with those based on pharmacy records. J Clin Epidemiol. 2005;58(9):924-933.

44. Clifford S, Barber N, Horne R. Understanding different beliefs held by adherers, unintentional nonadherers, and intentional nonadherers: application of the Necessity-Concerns Framework. J Psychosom Res. 2008;64(1):41-46.

45. Zwikker H, van den Bemt B, Vriezekolk J, van den Ende C, Van Dulmen S. Psychosocial predictors of non-adherence to chronic medication: systematic review of longitudinal studies. Patient Prefer Adherence. 2014;8:519-563. 


\section{Supplementary materials}

To obtain a dichotomous Compliance Questionnaire Rheumatology (CQR) non-adherence score, first a discriminant $Z$ score (which has been validated against a Medication Event Monitoring System [MEMS] taking compliance of $\leq 80 \%$ ) has to be calculated.

The CQR has 19 items, which reflect statements about drug-taking behavior. Patients respond to a 4-point Likert scale ranging from 1, "don't agree at all," to 4, "agree very much"; items 4, 8, 9, 11, 12, and 19 have to be reversely recoded $(4=1,3=2$, etc). Missing items are substituted with the patient's average on all non-missing items when the amount of missing items is smaller than four; otherwise, no score is calculated. The $Z$ score is calculated by means of the following function:

$$
\begin{aligned}
& Z \text { score }=-3.4777-(0.4448 * \operatorname{cqr} 1)-(0.9517 * \text { cqr } 2) \\
& +(1.6758 * \operatorname{cqr} 3)-(0.2101 * \operatorname{cqr} 4)+ \\
& (0.0244 * \text { cqr } 5)-(0.5353 * \text { cqr6 })+(0.003 * \text { cqr } 7)+ \\
& (0.0135 * \text { cqr8 })-(0.0106 * \text { cqr } 9)-(0.2546 * \text { cqr } 10) \\
& +(0.1023 * \operatorname{cqr} 11)+\left(0.1155^{*} \operatorname{cqr} 12\right) \\
& +(0.0248 * \operatorname{cqr} 13)+(0.1091 * \operatorname{cqr} 14) \\
& +(0.4475 * \operatorname{cqr} 15)+(0.2284 * \operatorname{cqr} 16) \\
& +(0.535 * \operatorname{cqr} 17)-(0.4191 * \operatorname{cqr} 18)+ \\
& \text { (0.6829*cqr19). }
\end{aligned}
$$

\begin{tabular}{|c|c|c|}
\hline $\begin{array}{l}\text { Secondary outcome } \\
\text { measure }\end{array}$ & Questionnaire & Description \\
\hline $\begin{array}{l}\text { Rheumatoid arthritis } \\
\text { (RA) disease activity }\end{array}$ & $\begin{array}{l}\text { Rheumatoid } \\
\text { Arthritis Disease } \\
\text { Activity Index } \\
(\text { RADAI) }\end{array}$ & $\begin{array}{l}\text { Five items, measuring global disease activity/pain, current duration of morning stiffness, } \\
\text { and current tender joints. Score range: } 0-10, \text { with higher scores indicating more } \\
\text { disease activity }\end{array}$ \\
\hline $\begin{array}{l}\text { Patient's usual } \\
\text { abilities in past week }\end{array}$ & $\begin{array}{l}\text { Health Assessment } \\
\text { Questionnaire } \\
\text { Disability Index } \\
(\text { HAQ-DI) })^{3}\end{array}$ & $\begin{array}{l}\text { Twenty items, measuring eight dimensions of functioning (dressing and grooming, arising, } \\
\text { eating, walking, hygiene, reaching, gripping, and common daily activities). Greater than } \\
\text { or equal to six dimensions need a valid score to obtain the total score. Score range: } \\
0-3 \text {, with higher scores indicating more disability. Note that we took aids and devices } \\
\text { into account in calculating the HAQ-DI score }\end{array}$ \\
\hline Pain severity & $\begin{array}{l}\text { HAQ Visual Analog } \\
\text { Scale (VAS) })^{3,4}\end{array}$ & Scale range: $0 \mathrm{~mm}$ (no pain) to $100 \mathrm{~mm}$ (unbearable pain) \\
\hline Illness cognitions & $\begin{array}{l}\text { Illness Cognition } \\
\text { Questionnaire } \\
(\mathrm{ICQ})^{5}\end{array}$ & $\begin{array}{l}\text { Three subscales of six items each, measuring "helplessness" as a way of emphasizing } \\
\text { the aversive meaning of a disease, "acceptance" as a way to diminish this aversive meaning, } \\
\text { and "perceived benefits" as a way of adding a positive meaning to a disease. Score range: } \\
6-24 \text {, with higher scores indicating more helplessness, acceptance, and perceived benefits }\end{array}$ \\
\hline Self-efficacy & $\begin{array}{l}\text { Arthritis Self-Efficacy } \\
\text { Scale (UVR) })^{6,7}\end{array}$ & $\begin{array}{l}\text { Measures the patient's perceived ability to perform specific behaviors aimed at controlling } \\
\text { disability. The UVR has three subscales: self-efficacy related to physical function (eight items), } \\
\text { to coping with pain (five items), and to coping with other symptoms associated with arthritis } \\
\text { (such as depression and fatigue, six items) } \\
\text { Score range: I-5, with higher scores indicating stronger self-efficacy }\end{array}$ \\
\hline $\begin{array}{l}\text { Anxiety and } \\
\text { depression }\end{array}$ & $\begin{array}{l}\text { Hospital Anxiety and } \\
\text { Depression Scale } \\
(\text { HADS) }\end{array}$ & $\begin{array}{l}\text { I } 4 \text { items, total score range: } 0-42 \text {, with higher scores indicating a higher degree of anxiety/ } \\
\text { depression } \\
\text { The HADS has two subscales, one for anxiety and one for depression, with seven items per } \\
\text { scale. Subscale score range: } 0-2 \text { I; subscale scores higher than } 8 \text { are indicative of anxiety } \\
\text { or depression }\end{array}$ \\
\hline
\end{tabular}

Non-adherence is defined when subjects have a $Z$ score $<-0.5849$. For more information about the CQR, see de Klerk et al.

Table SI Details of used questionnaires (except beliefs and adherence)

Note: All items in a questionnaire need a valid answer to obtain a total score, unless mentioned otherwise. 
Table S2 The contribution of single, psychological factors to associations between beliefs about medication and CQR non-adherence (corrected for demographic and clinical factors)

\begin{tabular}{|c|c|c|c|c|c|c|c|c|c|}
\hline & \multicolumn{9}{|c|}{ CQR non-adherence, OR (95\% Cl) } \\
\hline & \multirow{2}{*}{$\begin{array}{l}\text { Necessity } \\
\text { beliefs }\end{array}$} & \multirow{2}{*}{$\begin{array}{l}\text { Concern } \\
\text { beliefs }\end{array}$} & \multirow{2}{*}{$\begin{array}{l}\text { NC } \\
\text { differential }\end{array}$} & \multirow{2}{*}{$\begin{array}{l}\text { Overuse } \\
\text { beliefs }\end{array}$} & \multirow{2}{*}{$\begin{array}{l}\text { Harm } \\
\text { beliefs }\end{array}$} & \multicolumn{4}{|c|}{ Attitudinal profiles } \\
\hline & & & & & & Skeptical & Indifferent & Ambivalent & Accepting \\
\hline $\begin{array}{l}\text { Basic, adjusted model } \\
\text { (including demographic } \\
\text { and clinical variables)* }\end{array}$ & $\begin{array}{l}0.8 \\
(0.8-0.9)^{\#}\end{array}$ & $\begin{array}{l}.0 \\
(0.9-1.1)\end{array}$ & $\begin{array}{l}0.9 \\
(0.9-1.0)^{\#}\end{array}$ & $\begin{array}{l}\mathrm{I} . \mathrm{I} \\
(1.0-1.2)^{\ddagger}\end{array}$ & $\begin{array}{l}\text { I.I } \\
(1.0-1.2)\end{array}$ & $\begin{array}{l}\text { I.8 } \\
(0.5-5.9)\end{array}$ & $\begin{array}{l}5.0 \\
(1.3-19.3)^{\ddagger}\end{array}$ & $\begin{array}{l}0.8 \\
(0.5-1.4)\end{array}$ & $\begin{array}{l}0.9 \\
(0.5-1.5)\end{array}$ \\
\hline + ICQ helplessness ${ }^{\S}$ & - & - & - & - & - & - & - & $\begin{array}{l}0.9 \\
(0.5-1.6)\end{array}$ & $\begin{array}{l}0.8 \\
(0.5-1.3)\end{array}$ \\
\hline + ICQ acceptancell & - & - & - & - & - & - & - & $\begin{array}{l}0.6 \\
(0.4-I . I)\end{array}$ & $\begin{array}{l}\text { I.I } \\
(0.6-1.9)\end{array}$ \\
\hline $\begin{array}{l}\text { + ICQ perceived } \\
\text { benefits }\end{array}$ & - & - & - & - & - & - & $\begin{array}{l}6.9 \\
(1.5-32.2)^{\ddagger}\end{array}$ & $\begin{array}{l}0.7 \\
(0.4-1.2)\end{array}$ & $\begin{array}{l}1.0 \\
(0.6-1.6)\end{array}$ \\
\hline + UVR self-efficacy pain & - & - & - & - & - & - & - & - & - \\
\hline $\begin{array}{l}\text { + UVR self-efficacy } \\
\text { physical functioning }\end{array}$ & - & - & - & - & - & - & - & - & - \\
\hline $\begin{array}{l}\text { + UVR self-efficacy } \\
\text { symptoms }\end{array}$ & - & - & - & - & - & - & - & - & - \\
\hline $\begin{array}{l}\text { + HADS anxiety/ } \\
\text { depression }\end{array}$ & - & - & - & - & - & - & - & - & - \\
\hline
\end{tabular}

Notes: *Each of these models is adjusted for age, sex, living with others (yes/no), high education (yes/no), currently employed or studying (yes/no), disease duration, $n$ DMARDs used, route of DMARD administration, disease activity (RADAI) and pain (VAS). ${ }^{*} \leq 0.01$. ${ }^{\ddagger} \leq 0.05$. \$Basic, adjusted model (corrected for demographic and clinical variables) and ICQ helplessness. "Basic, adjusted model (corrected for demographic and clinical variables) and ICQ acceptance (etc). Data are shown as CQR non-adherence, OR $(95 \% \mathrm{Cl})$.

Abbreviations: CQR, Compliance Questionnaire Rheumatology; OR, odds ratio; NC, necessity concerns; ICQ, Illness Cognition Questionnaire; UVR, Arthritis Self-Efficacy Scale; HADS, Hospital Anxiety and Depression Scale; RADAI, Rheumatoid Arthritis Disease Activity Index; VAS, Visual Analog Scale; $n$ DMARDs, number of diseasemodifying antirheumatic drugs.

\section{References}

1. de Klerk E, van der Heijde D, Landewe R, van der Tempel H, van der Linden S. The compliance-questionnaire-rheumatology compared with electronic medication event monitoring: a validation study. J Rheumatol. 2003;30(11):2469-2475.

2. Fransen J, Langenegger T, Michel BA, Stucki G. Feasibility and validity of the RADAI, a self-administered rheumatoid arthritis disease activity index. Rheumatology (Oxford). 2000;39(3):321-327.

3. Bruce B, Fries JF. The Stanford Health Assessment Questionnaire: dimensions and practical applications. Health Qual Life Outcomes. 2003;1:20.

4. Price DD, Bush FM, Long S, Harkins SW. A comparison of pain measurement characteristics of mechanical visual analogue and simple numerical rating scales. Pain. 1994;56:217-226.
5. Evers AW, Kraaimaat FW, van Lankveld W, Jongen PJ, Jacobs JW, Bijlsma JW. Beyond unfavorable thinking: the illness cognition questionnaire for chronic diseases. J Consult Clin Psychol. 2001;69(6): 1026-1036.

6. Lorig K, Chastain RL, Ung E, Shoor S, Holman HR. Development and evaluation of a scale to measure perceived self-efficacy in people with arthritis. Arthritis Rheum. 1989;32(1):37-44.

7. Riemsma RP, Taal E, Rasker JJ. Group education for patients with rheumatoid arthritis and their partners. Arthritis Rheum. 2003;49(4):556-566.

8. Zigmond AS, Snaith RP. The hospital anxiety and depression scale. Acta Psychiatr Scand. 1983;67(6):361-370.
Patient Preference and Adherence

\section{Publish your work in this journal}

Patient Preference and Adherence is an international, peer-reviewed, open access journal that focuses on the growing importance of patient preference and adherence throughout the therapeutic continuum. Patient satisfaction, acceptability, quality of life, compliance, persistence and their role in developing new therapeutic modalities and compounds to optimize

\section{Dovepress}

clinical outcomes for existing disease states are major areas of interest for the journal. This journal has been accepted for indexing on PubMed Central. The manuscript management system is completely online and includes a very quick and fair peer-review system, which is all easy to use. Visit http://www. dovepress.com/testimonials.php to read real quotes from published authors. 